\title{
PEMANFATAN SAMPAH PLASTIK JENIS HDPE MENJADI BAHAN BAKAR ALTERNATIF PROSES PYROLYSIS
}

\author{
Nuryosuwito ${ }^{1)}$, Mokhamad Amirudin Ibnu Rosydi' ${ }^{2)}$, Hesti Istiqlaliyah ${ }^{3)}$ \\ ${ }^{1,2,3)}$ Program Studi Teknik Mesin, Universitas Nusantara PGRI Kediri \\ E-mail: nuryosuwito@unpkdr.ac.id, ${ }^{2}$ Barkoom2007@yahoo.com, \\ ${ }^{3)}$ hestiisti@gmail.com.
}

\begin{abstract}
Abstrak
Penelitian ini dilatarbelakangi karena semakin menumpuknya sampah plastik yang sulit terurai mengakibatkan pencemaran lingkungan. Dalam hal ini peneliti mengaitkan permasalahan yang ada di masyarakat dengan mencoba memanfaatkan sampah plastik jenis HDPE sebagai bahan bakar alternatif dengan menggunakan proses pyrolysis. Pyrolysis sendiri adalah pengolahan sampah dengan menggunakan metode thermal atau metode pembakaran tanpa menggunakan oksigen. Tujuan dari penelitian ini adalah ntuk mengetahui pemanfaatan sampah plastik jenis HDPE menjadi bahan bakar alternatif dengan proses pyrolysis. Metode yang digunakan dalam penelitian ini adalah metode eksperimental nyata. Dengan bahan sebagai variabel bebas dan nialai viskositas, densitas serta flash point sebagai variabel terikatnya. Sementara suhu kondensor dan tekanan sebagai variabel kontrol. Dari hasil penelitian yang telah dilakukan, pada suhu $250^{\circ} \mathrm{C}$ hasil cair berwarna pekat dan terdapat endapan, dengan nilai viskositas $0,3 \mathrm{dPa} . \mathrm{S}$, Densitas $750 \mathrm{Kg} / \mathrm{m}^{3}$ dan Flash point $34^{\circ} \mathrm{C}$. selanjutnya pada suhu $300{ }^{\circ} \mathrm{C}$ hasil cair berwarna merah tua jernih tanpa adanya endapan hasil cair dari suhu $300{ }^{\circ} \mathrm{C}$ ini merupakan hasil cair terbaik dibandingkan dengan suhu yang lain dengan nilai viskositas $0,29 \mathrm{dPa} . \mathrm{S}$, Densitas $740 \mathrm{Kg} / \mathrm{m}^{3}$ dan Flash point $32{ }^{\circ} \mathrm{C}$. Pada suhu $350{ }^{\circ} \mathrm{C}$ hasil cair berwarna merah tua jernih seperti pada suhu $300{ }^{\circ} \mathrm{C}$ tetapi pada suhu $350{ }^{\circ} \mathrm{C}$ terdapat endapan, dengan nilai viskositas $0,3 \mathrm{dPa} . S$, Densitas $750 \mathrm{Kg} / \mathrm{m}^{3}$ dan Flash point 33 ${ }^{\circ} \mathrm{C}$. pada suhu $400{ }^{\circ} \mathrm{C}$ hasil cair berwarna pekat dan terdapat banyak endapan dengan nilai viskositas $0,31 \mathrm{dPa} . \mathrm{S}$, Densitas $760 \mathrm{Kg} / \mathrm{m}^{3}$ dan Flash point $34{ }^{\circ} \mathrm{C}$.
\end{abstract}

Kata kunci : HDPE, Pirolisis, Plastik

\begin{abstract}
This research is caused by the increasing of plastic waste that difficult to decompose and become environmental pollution. from this problem, researchers trying to use HDPEtype plastic waste as an alternative fuel by using pyrolysis process. Pyrolysis is the processing of waste using thermal methods or combustion methods without the use of oxygen. The purpose of this research is to find out the utilization of HDPE type plastic waste into alternative fuels with pyrolysis process. The method used experimental method. With the material as a free variable and viscosity, density and flash point value as the bound variable. While condenser temperature and pressure as variable controls. From the research, at a temperature of $250^{\circ} \mathrm{C}$ the liquid results are concentrated in color and there are deposits, with a viscosity value of $0.3 \mathrm{dPa} . \mathrm{S}$, Density of $750 \mathrm{Kg} / \mathrm{m3}$ and Flash point of $34^{\circ} \mathrm{C}$. At a temperature of $300^{\circ} \mathrm{C}$ the liquid result is clear dark red in the absence of liquid deposits. From a temperature of $300{ }^{\circ} \mathrm{C}$ is the best liquid result compared to other temperatures with a viscosity value of $0.29 \mathrm{dPa} . S$, Density $740 \mathrm{Kg} / \mathrm{m} 3$ and Flash point $32{ }^{\circ} \mathrm{C}$. At a temperature of $350^{\circ} \mathrm{C}$ the liquid results are clear dark red as
\end{abstract}


at $300{ }^{\circ} \mathrm{C}$ but at a temperature of $350{ }^{\circ} \mathrm{C}$ there are deposits, with a viscosity value 0.3 dPa.S, Density $750 \mathrm{Kg} / \mathrm{m3}$ and Flash point $33{ }^{\circ} \mathrm{C}$. At a temperature of $400{ }^{\circ} \mathrm{C}$ liquid results are concentrated and there are many deposits with a viscosity value of $0.31 \mathrm{dPa} . \mathrm{S}$. Density $760 \mathrm{Kg} / \mathrm{m3}$ and Flash point $34^{\circ} \mathrm{C}$.

Keyword : HDPE, Pyrolisis, Plastic

\section{PENDAHULUAN}

Dalam perkembangannya penggunaan motor yang semakin meningkat menyebabkan kelangkaan pada bahan bakar. Kelangkaan baha bakar ini menyebabkan aktivitas masyarakat terganggu. Semakin hari jumlah kendaraan semakin meningkat dan jumlah ketersediaan akan bahan bakar mulai berkurang. Jika tidak segera ditangani dan diganti dengan bahan bakar alternatif masyarakat akan sangat kewalahan.

Disamping itu menumpukkan sampah juga menjadi masalah yang urgent bagi masyarakat, terutama sampah plastik. Dalam kehidupannya masyarakat tidak bisa lepas dari yang namnya plastik. Mulai dari urusan rumah tangga hingga industry. Sampah plastik yang sulit diurai oleh mikroorganisme akan menyebabkan penumpukan yang dapat mengganggu kesehatan masyarakat. Pengolahan sampah sampai saat ini hanya sebatas di bakar. Pembakaran sampah ini bisa menyebabkan gangguan pernapasan dan penyakit lainnya.

Permasalahan sampah menjadi semakin serius seiring dengan meningkatnya produksi sampah dari tahun ke tahun. Berdasarkan data Bank Dunia, jumlah sampah padat di kota-kota dunia akan terus naik sebesar $70 \%$ tahun ini hingga tahun 2025, dari 1,3 miliar ton per tahun menjadi 2,2 miliar ton per tahun. Mayoritas kenaikan terjadi di kotakota di negara berkembang. Di Indonesia, data Bank Dunia menyebutkan, produksi Sampah padat secara nasional mencapai 151.921 ton per hari. Hal ini berarti, setiap penduduk Indonesia membuang sampah padat rata-rata $0,85 \mathrm{~kg}$ per hari. Data yang sama juga menyebutkan, dari total sampah yang dihasilkan secara nasional, hanya $80 \%$ yang berhasil dikumpulkan, sisanya terbuang mencemari lingkungan[1].

Dalam hal ini peneliti mengaitkan permasalahan yang ada di masyarakat dengan mencoba memanfaatkan sampah plastik jenis HDPE sebagai bahan bakar alternatif dengan menggunakan proses pyrolysis. Pirolisis adalah proses dekomposisi bahan 
organik dan polimer dengan memanaskan bahan tersebut tanpa oksigen untuk menghasilkan produk-produk dengan berat molekul yang lebih rendah[2].

Berdasarkan analisa yang pernah dilakukan Lembaga Minyak dan Gas Bumi (Lemigas), minyak dari plastik bekas ini memiliki sifat tidak jenuh. Artinya, perbandingan antara karbon dan hidrogen tidak seimbang sehingga ada mata rantai yang tidak terisi. Minyak berwarna kuning kecokelatan, tetapi sudah bisa untuk bahan bakar kompor atau obor [3].

Minyak hasil pyrolysis ini mudah terbakar, mengeluarkan jelaga, dan baunya merangsang. Minyak pyrolysis ini dapat diolah lagi supaya mempunyai sifat jenuh dan stabil. Minyak pirolisis dari plastik polietilena, hasil penelitian menunjukkan bahwa minyak pirolisis dari plastik polietilena mempunyai densitas $939 \mathrm{~kg} / \mathrm{m} 3$ atau lebih berat dari minyak tanah. Minyak bakar ini mempunyai ignition point $30,4^{\circ} \mathrm{C}$ sehingga sangat mudah dinyalakan.

Plastik memiliki banyak kelebihan dibandingkan bahan lainnya. Secara umum, plastik memiliki densitas yang rendah, bersifat isolasi terhadap listrik, mempunyai kekuatan mekanik yang bervariasi, ketahanan suhu terbatas, serta ketahanan bahan kimia yang bervariasi. Selain itu, plastik juga ringan, mudah dalam perancangan, dan biaya pembuatan murah. Sebagian besar plastik yang digunakan masyarakat merupakan jenis plastik polietilena.

Ada beberapa jenis plastik yang umum ada di dalam kehidupan sehari-hari beserta kegunaannya [4].

\begin{tabular}{|c|l|l|}
\hline $\begin{array}{c}\text { No. } \\
\text { Kode }\end{array}$ & \multicolumn{1}{|c|}{ Jenis Plastik } & \multicolumn{1}{c|}{ Penggunaan } \\
\hline 1 & $\begin{array}{l}\text { PET (polyethylene } \\
\text { terephthalate })\end{array}$ & $\begin{array}{l}\text { botol kemasan air mineral, botol minyak } \\
\text { goreng, jus, botol sambal, botol obat, dan } \\
\text { botol kosmetik }\end{array}$ \\
\hline 2 & $\begin{array}{l}\text { HDPE (High-density } \\
\text { Polyethylene) }\end{array}$ & $\begin{array}{l}\text { botol obat, botol susu cair, jerigen pelumas, } \\
\text { dan botol kosmetik } \\
\text { pipa selang air, pipa bangunan, mainan, } \\
\text { taplak meja dari plastik, botol shampo, dan } \\
\text { botol sambal. }\end{array}$ \\
\hline
\end{tabular}

Pemanfatan Sampah Plastik Jenis Hdpe Menjadi Bahan Bakar Alternatif Proses Pyrolysis (Nuryosuwito, Mokhamad Amirudin Ibnu Rosydi, Hesti Istiqlaliyah) 


\begin{tabular}{|c|l|l|}
\hline 4 & $\begin{array}{l}\text { LDPE (Low-density } \\
\text { Polyethylene) }\end{array}$ & $\begin{array}{l}\text { kantong kresek, tutup plastik, plastic } \\
\text { pembungkus daging beku, dan berbagai } \\
\text { macam plastik tipis lainnya. }\end{array}$ \\
\hline 5 & $\begin{array}{l}\text { PP (Polypropylene atau } \\
\text { Polypropene) }\end{array}$ & $\begin{array}{l}\text { cup plastik, tutup botol dari plastik, mainan } \\
\text { anak, dan margarine }\end{array}$ \\
\hline 6 & PS (Polystyrene) & $\begin{array}{l}\text { kotak CD, sendok dan garpu plastik, gelas } \\
\text { plastik, atau tempat makanan dari } \\
\text { styrofoam, dan tempat makan plastik } \\
\text { transparan }\end{array}$ \\
\hline 7 & $\begin{array}{l}\text { Other (O) } \\
\text { Jenis plastik lainnya } \\
\text { selain dari no.1 hingga 6 }\end{array}$ & $\begin{array}{l}\text { Botol susu bayi, plastik kemasan, gallon air } \\
\text { minum, suku cadang mobil, alat-alat rumah } \\
\text { tangga, komputer, alat-alat elektronik, sikat } \\
\text { gigi, dan mainan lego }\end{array}$ \\
\hline
\end{tabular}

Penelitian mengenai pengaruh temperatur dan waktu terhadap hasil char pada proses pyrolysis, dimana semakin tinggi temperatur setelah melewati temperatur puncak, reaktifitas dari char akan menurun. Sedangkan komponen waktu tidak terlalu berpengaruh terhadap terhadap reaktifitas dari char. Oleh karena itu salah satu variasi pada penelitian yang akan dilakukan adalah variasi suhu.

\section{METODE PENELITIAN}

Metode yang digunakan dalam penelitian ini menggunakan metode eksperimental nyata (true experimental research). Menurut Solso, penelitian eksperimental adalah dimanipulasi untuk mempelajari hubungan sebab-akibat[5]. Sedangkan menurut Sugiyono, penelitian eksperimen adalah metode penelitian yang digunakan untuk mencari pengaruh perlakuan tertentu terhadap yang lain dalam kondisi-kondisi yang terkendalikan[6]. Metode ini dilaksanakan dengan melakukan pengujian untuk mengetahui nilai viskositas, densitas dan flash point dari sampah plastik jenis HDPE dengan proses pirolisis. Serta untuk mengetahui bagaimana proses pirolisis tersebut dapat bekerja dengan baik dan efisien. 
Variabel bebas dalam penelitian ini adalah temperatur tabung reaktor yang dikondisikan $250^{\circ} \mathrm{C}, 300^{\circ} \mathrm{C}$, dan $350^{\circ} \mathrm{C}$. Variabel terikat dalam penelitian ini adalah:

a. Perolehan hasil pirolisis dalam bentuk cair ditinjau dari temperature tabung reaktor.

b. Nilai viskositas hasil pirolisis ditinjau dari temperatur tabung reaktor.

c. Nilai massa jenis (densitas) hasil pirolisis ditinjau dari temperatur tabung reaktor.

d. Nilai flash point hasil pirolisis ditinjau dari temperatur tabung reaktor.

Variabel kontrol yang digunakan peneliti adalah waktu temperatur yaitu 1 jam.

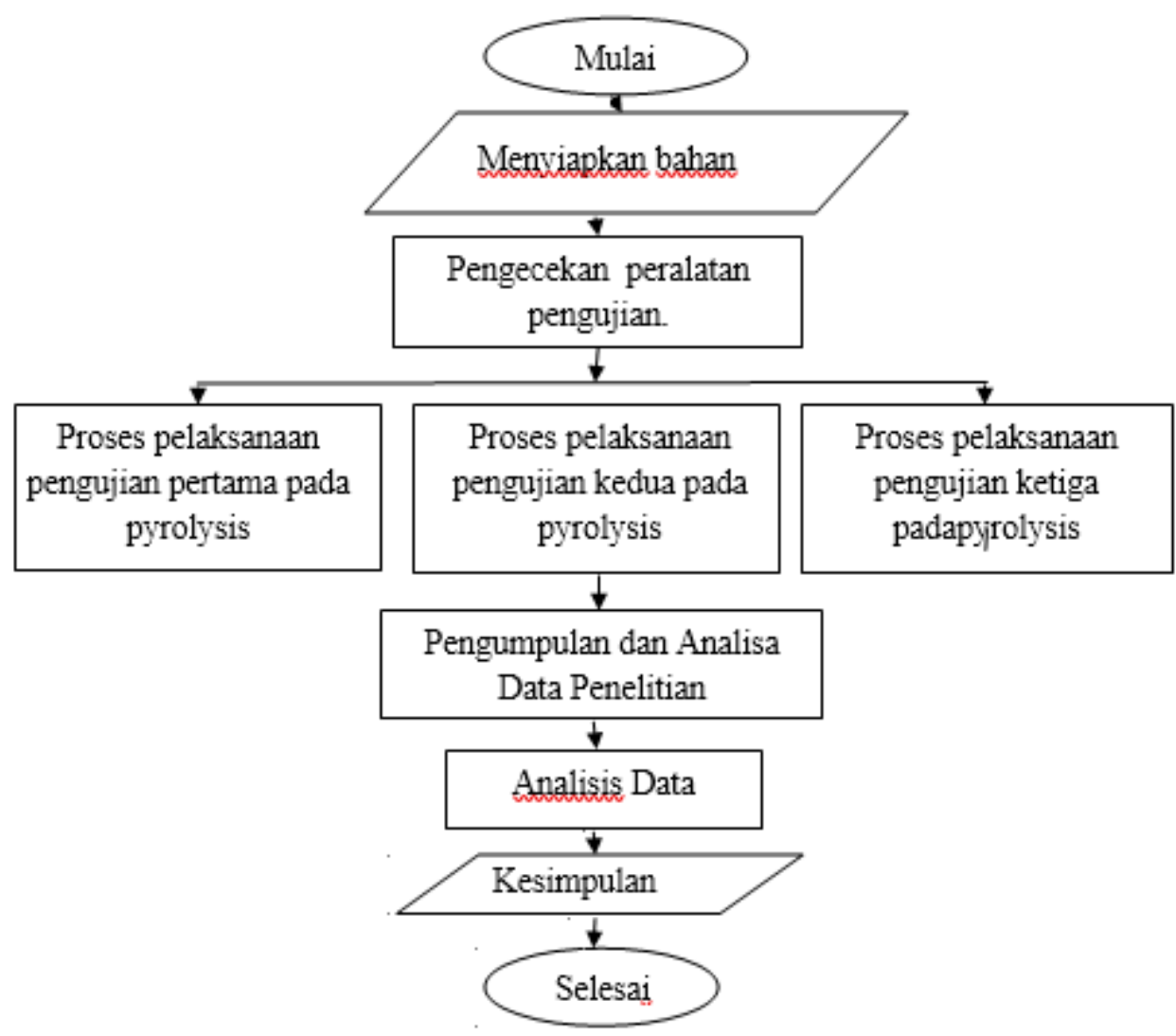

Gambar 1. Diagram alir 


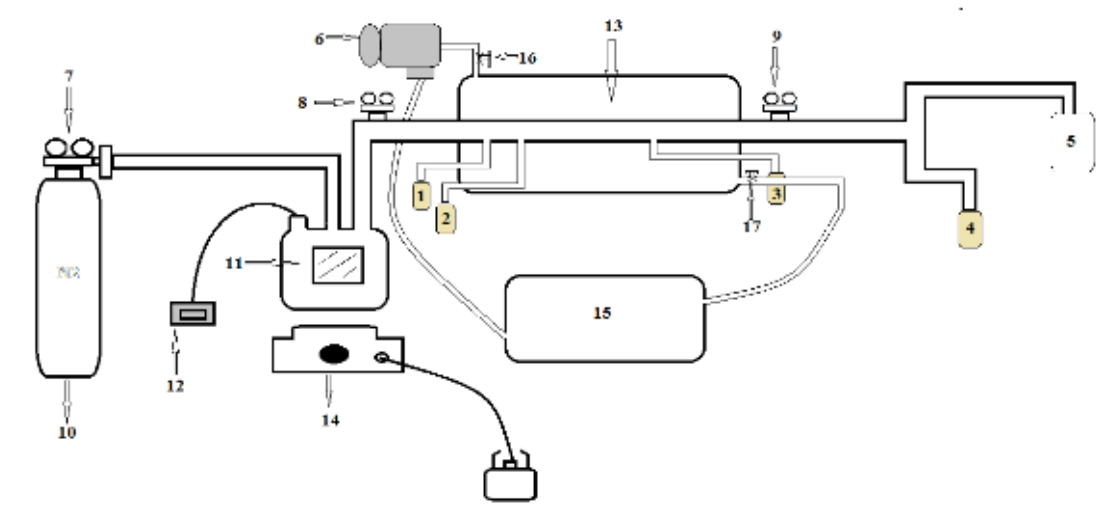

Gambar 2. Instalasi Peralatan Pengujian

Pada gambar 2, sampel sampah (1) yang akan di pyrolysis dimasukkan kedalam wadah sampel (2), wadah berisi sampel digantungkan dengan kawat pada timbangan digital (3), salah satu ujung thermocouple (4) diletakka nsedikit diatas sampel dan ujung thermocouple yang lain tertanam dalam sampel tetapi sedikit diatas pada bagian bawah wadah sampel, bak pendingin (5) di isi air, nitrogen dialirkan dari tabung (6) dengan laju aliran yang dapat diatur dengan menggunakan pengaturan rotameter (7), ketika furnace dipanaskan (8) dengan menghidupkan thermocontroller (9), variasi temperatur akhir dapat diatur sesuai dengan kebutuhan. Perubahan volume gas yang dihasilkan dari proses pyrolysis diukur dengan menggunakan tabung berisi air (13) dan gelas ukur (14).

Setelah pengambilan data pyrolysis selanjutnya hasil data dari perolehan pyrolysis akan dimasukkan kedalam tabel 1 sebagai berikut.

Tabel 1. Pengambilan data

\begin{tabular}{|c|c|c|c|c|c|}
\hline No. & Bahan & $\begin{array}{c}\text { Berat } \\
\text { (kg) }\end{array}$ & $\begin{array}{c}\text { Suhu } \\
\left({ }^{0} \mathbf{c}\right)\end{array}$ & $\begin{array}{r}\text { Waktu } \\
\text { (menit) }\end{array}$ & $\begin{array}{c}\text { Hasil } \\
\text { Cair }(\mathrm{ml})\end{array}$ \\
\hline & \multirow{8}{*}{$\begin{array}{c}\text { Sampah } \\
\text { platik } \\
\text { HDPE }\end{array}$} & \multirow[t]{8}{*}{$5 \mathrm{~kg}$} & 250 & & \\
\hline & & & & & \\
\hline & & & & & \\
\hline & & & 300 & & \\
\hline & & & & & \\
\hline & & & 350 & & \\
\hline & & & & & \\
\hline & & & & & \\
\hline
\end{tabular}


Setelah pengamatan tentang jumlah perolehan hasil pirolisis, maka selanjutnya hasil cairan di teliti tentang nilai karakteristiknya yaitu tentang nilai viskositas, nilai densitas dan nilai flash point. Kemudian hasil pengujian dimasukkan ke dalam tabel pengukuran viskositas, densitas dan flash pointberikut:

Tabel 2. Pengukuran Viskositas

\begin{tabular}{|c|c|c|c|}
\hline Bahan & SAMPAH HDPE & 350 \\
\hline Temperatur $\left({ }^{\circ} \mathrm{C}\right)$ & 250 & 300 & \\
\hline Viscositas (dPa.S) & & & \\
\hline
\end{tabular}

Tabel 3. Pengukuran Densitas

\begin{tabular}{|c|c|c|c|c|}
\hline No. & Temperatur $\left({ }^{\mathbf{o}} \mathbf{C}\right)$ & $\begin{array}{c}\text { Massa Cairan } \\
(\mathbf{K g})\end{array}$ & $\begin{array}{c}\text { Volume } \\
\left(\mathbf{m}^{\mathbf{3}}\right)\end{array}$ & $\begin{array}{c}\text { Densitas } \\
\left(\mathbf{K g} / \mathbf{m}^{\mathbf{3}}\right)\end{array}$ \\
\hline 1 & 250 & & & \\
\hline 2 & 300 & & & \\
\hline 3 & 350 & & & \\
\hline
\end{tabular}

Tabel 4. Pengukuran Flash Point

\begin{tabular}{|c|c|c|}
\hline No. & Temperatur $\left({ }^{\mathbf{0}} \mathbf{C}\right)$ & Flash Point $\left({ }^{\mathbf{C}} \mathbf{C}\right)$ \\
\hline 1 & 250 & \\
\hline 2 & 300 & \\
\hline 3 & 350 & \\
\hline
\end{tabular}

\section{HASIL DAN PEMBAHASAN}

Dari hasil eksperimen dapat diketahui dengan beberapa uji sehingga sebelum masuk hasil uji perlu diketahui dulu deskripsi hasil data pada setiap variabel.

\section{a. Deskripsi Hasil Data dan Pengujian}

Dalam penelitian ini variable bebasnya adalah sampah plastik jenis high density polyethylene (HDPE). Sampah plastik jenis HDPE akan ditimbang sebanyak $5 \mathrm{~kg}$ dan dimasukkan ke dalam tabung reactor. Data hasil pengamatan adalah sebagai berikut : 
Tabel 5.Hasil Pengujian

\begin{tabular}{|l|l|c|c|c|}
\hline \multirow{3}{*}{ Bahan } & \multirow{3}{*}{ Variabel Pengamatan } & \multicolumn{3}{|c|}{ Temperatur ${ }^{\mathbf{}} \mathbf{C}$} \\
\cline { 3 - 5 } & & $\mathbf{2 5 0}$ & $\mathbf{3 0 0}$ & $\mathbf{3 5 0}$ \\
\hline \multirow{5}{*}{ HDPE } & Suhu Kompor $\left({ }^{\circ} \mathrm{C}\right)$ & 401 & 492 & 525 \\
\cline { 2 - 5 } & Suhu Air $\left({ }^{\circ} \mathrm{C}\right)$ & 25 & 25 & 25 \\
\cline { 2 - 5 } & Suhu Kondensor $\left({ }^{\circ} \mathrm{C}\right)$ & 26 & 26 & 26 \\
\cline { 2 - 5 } & Suhu out Kondensor $\left({ }^{\circ} \mathrm{C}\right)$ & 26 & 27 & 27 \\
\cline { 2 - 5 } & Suhu Out Reaktor $\left({ }^{\circ} \mathrm{C}\right)$ & 28 & 30 & 53 \\
\cline { 2 - 5 } & Jumlah Cairan $(\mathrm{ml})$ & 180 & 210 & 268 \\
\cline { 2 - 5 } & Suhu Cairan $\left({ }^{\circ} \mathrm{C}\right)$ & 28 & 30 & 31 \\
\hline
\end{tabular}

Hasil di atas merupakan hasil pengujian Pengaruh suhu dan hasil yang diperoleh dalam pembakaran sampah plastik jenis HDPE dapat digambarkan pada grafik di bawah ini :

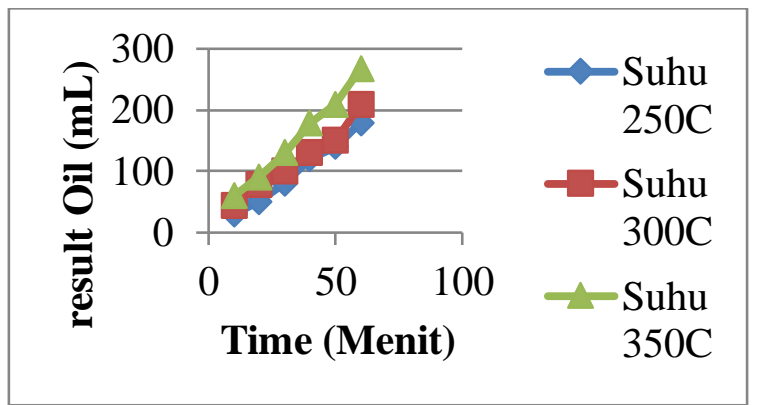

Gambar 3. Grafik perubahan temperatur terhadap hasil yang diperoleh dengan bahan high density polyethylene (HDPE).

Dari hasil pengujian viskositas mengunakan alat viscotester diperoleh hasil sebagai berikut :

Tabel 6. Hasil Pengukuran Viskositas

\begin{tabular}{|c|c|c|c|}
\hline Bahan & \multicolumn{3}{|c|}{ Sampah plastik HDPE } \\
\hline Temperatur $\left({ }^{\circ} \mathrm{C}\right)$ & 250 & 300 & 350 \\
\hline Viskositas (dPa.S) & 0,37 & 0,3 & 0,35 \\
\hline
\end{tabular}

Untuk mengetahui nilai densitas dari masing-masing sampel maka perlu diketahui massa dan volume dari zat cair. Sebelumnya gelas erlemeyer kosong dengan kapasitas volume $100 \mathrm{ml}$ ditimbang dan massa yang di dapat sebesar 0,073 $\mathrm{kg}$. Setelah itu gelas erlemeyer diisi dengan cairan sampel dengan volume $100 \mathrm{ml}$ dan ditimbang. Dari hasil pengukuran di dapat hasil sebagai berikut : 
Tabel 7. Pengukuran Hasil Densitas

\begin{tabular}{|c|c|c|c|}
\hline \multicolumn{1}{|c|}{ Bahan } & $\begin{array}{c}\text { Massa erlemeyer } \\
(\mathbf{K g})\end{array}$ & $\begin{array}{c}\text { Massa Erlemeyer } \\
\text { + Cairan (Kg) }\end{array}$ & $\begin{array}{c}\text { Massa } \\
\text { Cairan (Kg) }\end{array}$ \\
\hline \multirow{2}{*}{$\begin{array}{l}\text { Sampah } \\
\text { Plstik HDPE }\end{array}$} & 0,073 & 0,146 & 0.073 \\
\cline { 2 - 4 } & 0,073 & 0,144 & 0,071 \\
\cline { 2 - 4 } & 0,073 & 0,146 & 0,073 \\
\hline
\end{tabular}

Untuk mengetahui nilai flash point dari masing-masing sampel akan diukur menggunakan alat Flash Point Tester. Sampel akan dimasukkan ke dalam wadah dan diukur dengan menggunakan termometer, jika dalam suhu ruang sampel sudah bisa memercikkan api ketika diberi nyala api maka itu adalah titik flash point cairan tersebut, akan tetapi jika belum bisa memercikkan api maka sampel akan dipanasi hingga suhu tertentu sampai bisa memercikkan api ketika di beri nyala api. Berikut adalah tabel pengukuran flash point pada sampel dari bahan sampah plastik HDPE.

Tabel 8. Hasil Pengukuran flash point

\begin{tabular}{|c|c|c|c|}
\hline NO & Bahan & Temperatur $\left({ }^{\circ} \mathrm{C}\right)$ & Flash Point $\left({ }^{\circ} \mathrm{C}\right)$ \\
\hline \multirow{3}{*}{1} & \multirow{3}{*}{ Sampah Plastik HDPE } & 250 & 35 \\
\cline { 3 - 4 } & & 300 & 34 \\
\cline { 3 - 4 } & & 350 & 35 \\
\hline
\end{tabular}

\section{b. Pembahasan}

Menurut Penelitian pada suhu $250{ }^{\circ} \mathrm{C}$ cairan yang dihasilkan lebih kental dengan nilai viskositas $0,37 \mathrm{dPa} . \mathrm{S}$, hal ini disebabkan karena masih adanya bahan plastik yang belum terpanaskan dan partikel lain ikut keluar dari tabung dan larut dalalm cairan, dengan Densitas $730 \mathrm{Kg} / \mathrm{m}^{3}$ dan Flash point $35^{\circ} \mathrm{C}$. Selanjutnya pada suhu $300^{\circ} \mathrm{C}$ hasil cair dari suhu ini lebih jernih dan tidak ada endapan, pada suhu ini merupakan hasil cair terbaik dibandingkan dengan suhu yang lain dengan nilai viskositas 0,3 dPa.S, Densitas $710 \mathrm{Kg} / \mathrm{m}^{3}$ dan Flash point $34{ }^{\circ} \mathrm{C}$. Kemudian Pada suhu $350^{\circ} \mathrm{C}$ hasil cair lebih kental dan terdapat endapan sama seperti pada suhu $250{ }^{\circ} \mathrm{C}$, endapan tersebut disebabkan karena tingginya suhu pembakaran bahan plastik yang mencair ikut menguap dan jika endapan didiamkan akan mengeras seperti lilin dengan nilai viskositas 0,35 dPa.S, Densitas $730 \mathrm{Kg} / \mathrm{m}^{3}$ dan Flash point $35^{\circ} \mathrm{C}$. Proses pyrolysis adalah mendingankan uap panas yang dihasilkan dari pemanasan plastik. Jika panas terlalu tinggi . ini bukan hanya uap panas yang kluar 
dari tabung, melainkan cairan plastik juga ikut kluar, mengakibatkan cairan yang di hasilkan bercampur dengan plastik cair dan hasilnya menjadi kurang bagus.

\section{PENUTUP}

\section{a. Simpulan}

Berdasarkan hasil eksperimen dan analisa yang telah dilakukan, dapat diambil kesimpulan bahwa dengan proses pyrolysis sampah plastik jenis HDPE bisa digunakan sebagai bahan bakar akternatif karena memiliki sifat karakteristik yang seperti gasoline. Data hasil pengamatan pada suhu $250{ }^{\circ} \mathrm{C}$ dalam waktu 60 menit yang dihasilkan $120 \mathrm{ml}$ dan suhu $300^{\circ} \mathrm{C}$ yang dihasilkan $170 \mathrm{ml}$, sedangkan pada suhu $350{ }^{\circ} \mathrm{C}$ yang dihasilkan $220 \mathrm{ml}$. Jadi hasil cair terbanyak pada suhu 350 ${ }^{\circ} \mathrm{C}$.

\section{b. Saran}

Untuk mendapatkan hasil bahan bakar alternatif yang baik atau hasil cair lebih banyak gunakan bahan jenis high density polyetline (HDPE) sehinga dapat menghasilkan yang paling baik dan banyak. Disarankan untuk penelitian selanjutnya agar menguji factor lain yang dapat mempengaruhi hasil produk pyrolysis dengan beberapa varisai bahan yamg digunakan.

\section{DAFTAR PUSTAKA}

[1] Borsodi, N., Miskolczi, N., Angyal, A., Bartha,L.,Kohán,J.,dan Lengyel,A.. 2011. Hydrocarbonsobtained bypyrolysis of contaminated waste plastics. 45 th International Petroleum Conference. Bratislava. Slovak Republic.

[2] Das, S. dan Pande, S.. 2007. Pyrolysis and Catalytic Cracking of Municipal Plastic Waste for Recovery of Gasoline Range Hydrocarbons, Thesis, Chemical Engineering Department National Institute of Technology Rourkela

[3] Sumarni, 2008. Statika Untuk Penelitian. Jakarta: Tangga Pustaka.

[4] Nuryosuwito, Sudjito, Wijayanti, W., dan Sasongko M.N. 2018. Pengaruh Campuran Sampah Plastik Dengan Katalis Alam Terhadap Hasil Produk Pyrolisis. Jurnal Rekayasa Mesin Vol.9, No.2

[5] Solso dan Maclin. 2002. Penelitian Eksperimental. Jakarta: PT. Gramedia.

[6] Sugiyono, 2010. Metode Penelitian Kuantitatif Kualitatif \& RND. Bandung : Alfabeta. 